\title{
Enzyme Polymorphism as a Biochemical Cell Marker: Application to the Cellular Origin and Homogeneity of Human Macrophages and to the Classification of Malignant Lymphomas*
}

\author{
H. J. Radzun, M. R. Parwaresch, and K. Lennert
}

The polymorphism of enzyme systems can be ascribed to four different mechanisms. Physicochemical heterogeneity ensues from free combination of subunits constituting the quaternary structure of enzyme proteins. The so-called microheterogeneity is caused by the presence of nonpeptide groups in the enzyme molecules. Furthermore, genetic activity leads to the appearance of molecular enzyme variants called isoenzymes. Finally, the phenotypical expression of genetic variations is usually obscured by the inductive and repressive influences exerted during ontogenesis and differentiation. This is referred to as balanced polymorphism (Ford 1940).

There is ample evidence that the pattern of enzyme variants remains constant within a homogeneous cell population and reveals a stable feature specific to this cell cohort ( $\mathrm{Li}$ et al. 1970). We have used isoelectric focusing on polyacrylamide gels for investigation of the lysosomal acid esterase (EC 3.1.1.6) and lysosomal acid phosphatase (EC 3.1.3.2) polymorphism in purified human blood cell types (Radzun et al. 1980, to be published). It could be shown that clear differences in the pattern of enzyme variants were detectable between platelets, red blood cells, granulocytes, monocytes, and $\mathrm{T}$ and $\mathrm{B}$ lymphocytes.

The unique distribution pattern of acid esterase in human blood monocytes with four minor and one major anodic band within a $\mathrm{pH}$ range of 6.25-5.70 was used to detect the homogeneity and cellular origin of human peritoneal macrophages. Purified unstimulated sessile peritoneal macrophages, obtained

\footnotetext{
* This work was supported by the Deutsche Forschungsgemeinschaft, programs CL3 and CN2
}

from noninflammatory peritoneal cavity, showed in addition to the five isoenzymes of acid esterase which are specific for blood monocytes, two further enzyme variants (Fig. 1). Exposure of blood monocytes to an uncoated glass surface led to the appearance of these two bands on the third day of culture. From these results we deduce that sessile peritoneal macrophages, like exudate peritoneal macrophages, represent a monocytic cell cohort. Thus, all macrophages of the peritoneal cavity constitute a homogeneous cell population. This contradicts the opinion of other authors, who hold the view that sessile peritoneal macrophages are self-sustaining (Daems et al. 1973).

Another example for the application of cell-specific polymorphism of enzymes is its employment in the characterization of tumor cells. On the basis of morphological conventions and enzyme cytochemical and immunocytochemical methods, human malignant lymphomas have been successfully classified (Lennert et al. 1978). It has been shown that the four lymphoma entities - chronic lymphocytic leukemia of B-cell type, follicular lymphoma, lymphoplasmacytic/lymphoplasmacytoid lymphoma, and plasmacytoma - represent B lymphocyte neoplasias, imitating various stages of activity and differentiation of normal B lymphocytes. In line with these considerations all four lymphoma entities shared the isoenzyme pattern of lysosomal acid phosphatase observed in normal human B lymphocytes (Fig. 2). Furthermore, the stepwise rise in enzyme activity from one lymphoma entity to the next was at least partly due to the appearance of additional isoenzymes (Schmidt et al., to be published). These results show that it is possible to classify a tumor as B lymphocytic in origin on the basis of its typical isoenzyme 


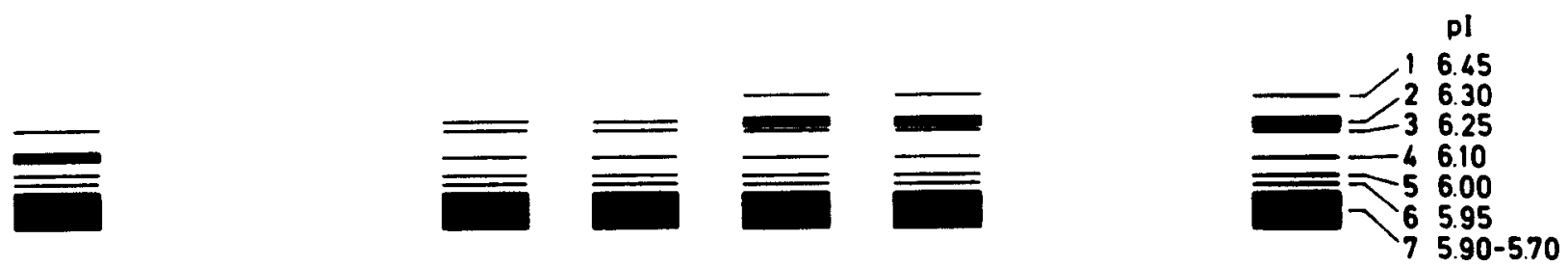

Fig. 1. Polymorphism of lysosomal acid esterase in normal human blood monocytes and sessile peritoneal macrophages. Prolonged exposure of blood monocytes to uncoated glass surface showed a gradual transition of the monocytic pattern of acid esterase into that of peritoneal macrophages. $p I$, isoelectric point

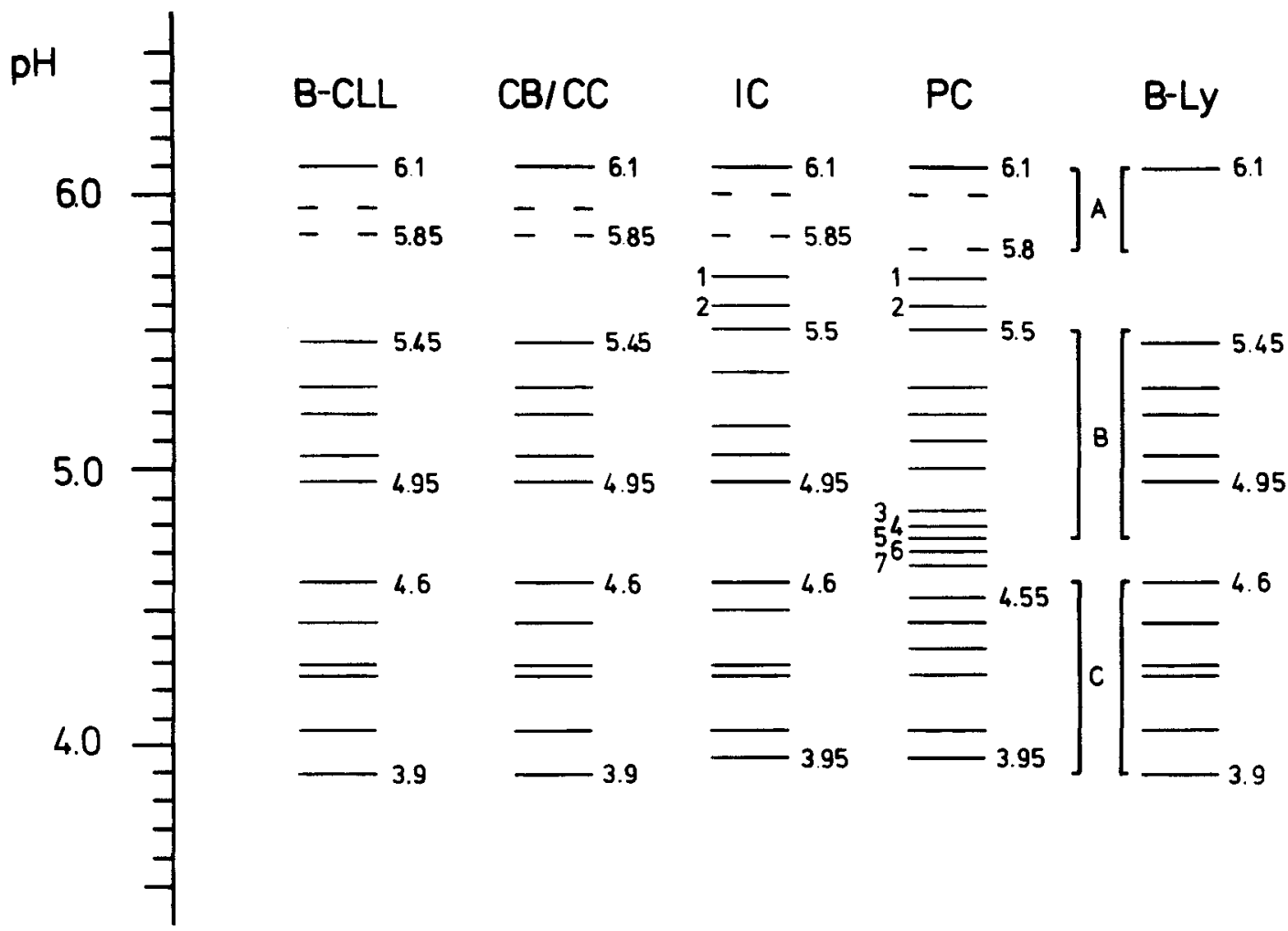

Fig. 2. Polymorphism of lysosomal acid phosphatase in chronic lymphocytic leukemia of B-cell type $(B-C L L)$, follicular lymphoma $(C B / C C)$, lymphoplasmacytic/lymphoplasmacytoid lymphoma $(I C)$, and plasmacytoma $(P C)$ in comparison with normal human B lymphocytes $(B-L y)$

pattern as long as pure populations of tumor cells are provided.

The examples mentioned above document the new perspectives of using enzyme polymorphism as a biochemical marker for the characterization of maturational stages, functional derivatives, and neoplastic variants of a certain cell line.

\section{References}

Daems WT, Poelman RE, Brederoo P (1973) Peroxidatic activity in resident peritoneal macropha- ges and exudate monocytes of the guinea pig after ingestion of latex particles. J. Histochem Cytochem 21:93-95 - Ford EB (1940) In: Huxley J (ed) The new systematics. Clarendon, Oxford, pp 493-513 - Lennert K, Stein H, Mohri N, Kaiserling E, Mueller-Hermelink KH (1978) Malignant lymphomas other than Hodgkin's disease. Springer, New York Berlin Heidelberg - Li CY, Yam LT, Lam KW (1970) Studies of acid phosphatase isoenzymes in human leucocytes. Demonstration of isoenzyme cell specificity. J Histochem Cytochem 18:901-910 - Radzun HJ, Parwaresch MR, Kulenkampff C Staudinger M, Stein H (1980) Lysosomal acid esterase: Activity and isoenzymes in separated normal human blood cells. Blood 55:891-897 - Radzun HJ, Parwaresch MR, Kulenkampff C, 
Stein H (1980) Lysosomal acid phosphatase: Activity and isoenzymes in separated normal human blood cells. Clin Chim Acta 102:227-235 - Schmidt D, Radzun HJ, Schwarze E, Stein H, Parwaresch MR
(1980) Activity and isoenzymes of acid phosphatase in human B-cell lymphoma of low grade malignancy. A novel aid in the classification of malignant lymphoma. Cancer 46:2676-2681 